\title{
Theoretical Investigation on Multiple Separation of Bridge under Near-Fault Vertical Ground Motion
}

\author{
Shutong Chen, Houzheng Xia, Wenjun An $\mathbb{D}$, and Yuwen Wen \\ Department of Civil Engineering, Jiangxi University of Engineering, Xinyu 330046, China \\ Correspondence should be addressed to Wenjun An; wjan@email.ncu.edu.cn
}

Received 16 December 2020; Accepted 9 August 2021; Published 25 August 2021

Academic Editor: Francesco Tornabene

Copyright ( 2021 Shutong Chen et al. This is an open access article distributed under the Creative Commons Attribution License, which permits unrestricted use, distribution, and reproduction in any medium, provided the original work is properly cited.

In order to consider the effect of near-field vertical earthquake, a model of a two-span continuous beam bridge is established. On the basis of superposition of longitudinal and vertical seismic actions, the possible separation of vertical earthquake is considered, and the influence of separation on structural failure is calculated. The transient wave characteristic function method and the indirect mode superposition method are used to solve the response theory of the bridge structure during the earthquake. When the vertical seismic excitation period is close to the vertical natural vibration period of the bridge, structure may separate. For the highpier-type bridge, the separation enlarges the deformation of the pier and even causes the pier failure. The external conditions such as the time difference of arrival of seismic wave and the stiffness of support will affect the deformation of bridge piers. In addition, the number of separations will also change the seismic response of the pier.

\section{Introduction}

As a transportation hub, bridges will cause serious damage to the road network when an earthquake occurs, which brings great difficulties to rescue work in the disaster-stricken areas. Simultaneously, it greatly affected the postdisaster recovery and reconstruction work and significantly reduced the traffic function between regions $[1,2]$. The collision between adjacent beams and between girder and abutment has been widely studied, and a series of research results have been obtained [3-16]. Various models are used to calculate the impact force [3-7] and how to design reasonably to reduce the impact on the structure [12-16]. However, there are few studies on the vertical impact force between the main beam and the pier under vertical seismic action, especially the eccentric collision phenomenon caused by the impact force on the pier.

According to the previous far-field seismic records $[17,18]$, peak acceleration of vertical earthquake is obviously smaller than that of horizontal earthquake. For structural design, there is a large safety factor in the vertical direction. Therefore, the vertical seismic component is usually considered to be unimportant in the design $[19,20]$. Seismic monitoring data show that the amplitude of vertical seismic acceleration exceeds the specified value. For example, in the Northridge earthquake in 1994, the ratio of vertical and horizontal acceleration amplitude $(\mathrm{V} / \mathrm{H})$ was as high as 1.79 [17]. The peak value of vertical and horizontal acceleration $\mathrm{V} / \mathrm{H}$ of Kobe earthquake in 1995 is close to 2 [18]. Analyzing nine pieces of data collected within $20 \mathrm{~km}$ of the Wenchuan earthquake source, the average acceleration ratio $\mathrm{V} / \mathrm{H}$ is 0.89 , and the maximum value is 1.2 [21]. In addition, there is an obvious peak in a short period of time, which is more than $2 / 3$ of that specified in most specifications [22].

Different from foreign rigid frame bridges, Chinese bridges, especially many small/medium-span bridges, mostly use rubber bearings, which bear compressive connection in vertical direction, but lack tensile restraint $[9,23]$. When a large vertical earthquake occurs in the near-fault aera, the serious resonance may cause the separation of the main beam and the bearing. In the 2011 Christchurch earthquake, some bridges, including the ANZAC Legion Drive Bridge, suffered vertical impact damage to their piers [24-27]. For the investigation of vertical impact, Yang et al. calculated the impact force of girder and bearing under different conditions by using numerical simulation [25]. Although there is a certain arrival time difference between 
the vertical earthquake and the horizontal earthquake, the bridge separation caused by the near-fault earthquake will not only produce a huge impact force, but also affect the horizontal displacement response, but there is no special analysis in the literature on the possible impact of the bridge pier damage caused by the separation. It is necessary to analyse the influence of the possible separation phenomenon on the damage of the horizontal bridge under the strong amplitude vertical earthquake motion.

In the past, the research on the impact force of adjacent structures is to simplify the bridge as a springlumped-mass model $[4,10,11]$. For the flexible characteristics of structures, some scholars use the finite element method to simulate the flexible collision of structures $[8,9,13-15]$. Recently, Yang et al. [25] used continuum model to calculate the vertical impact force between main girder and pier. However, this method cannot clearly explain the collision process, especially for the bearing stiffness changes, the calculation results may have large dispersion.

The main purpose of this analysis is to establish a theoretical method for reliable and accurate analysis of structural separation under vertical seismic action and to calculate the influence of vertical separation on horizontal displacement response. The calculation of resonance response adopts the method of transient wave function expansion, and the theoretical solutions of vertical and longitudinal seismic response are calculated by expanding the wave function into a series of characteristic functions. The indirect mode superposition method is used to calculate the vertical and longitudinal impact response.

\section{Theoretical Model}

The model used in this research is a double-span continuous bridge. The calculation model is shown in Figure 1. The main girder is a prestressed box beam, and pier is a double-column circular pier. In order to reduce the nonlinear bending of bridge pier caused by resonance, the high damping rubber bearing was selected. The round lead high damping rubber bearing was used. In the vertical direction, the hysteresis curve of the bearing was long and narrow, ignoring the damping of the vertical bearing. In the horizontal direction, the damping of the bearing was $\zeta_{1}=20 \%$. In the vertical direction, the stiffness of the bearing was $K_{c}=2.4 \times 10^{9} \mathrm{~N} / \mathrm{m}$; in the horizontal direction, the stiffness was $K_{v}=2.4 \times 10^{6} \mathrm{~N} / \mathrm{m}$. To simplify the calculation, this study makes the following assumptions:

(1) When the bridge was forced to resonate, the structural force and displacement response were always calculated by elastic deformation.

(2) The possible bearing shear failure caused by a horizontal earthquake is ignored.

(3) During seismic action, there were often stops in the lateral direction. This study only considers the coupling of vertical and longitudinal seismic activities.

(4) The difference in the arrival time of the horizontal and vertical seismic waves is ignored, assuming that the earthquakes in both directions were excited at the same time.

(5) The effect of the soil on the structure is ignored, assumed to be rigid.

2.1. Theoretical Solution of Displacement Response of Bridge in Vertical Contact Stage. Vertical displacement field $Y(x, t)$ of the girder can be divided into static displacement $Y_{s}$, rigid body displacement $Y_{g}$, and dynamic deformation $Y_{d}$. Pier displacement field $U(\xi, t)$ was similarly classified. $x$ is the distance from the middle span of the main girder, and $\xi$ is the distance from the base of the pier:

$$
\begin{aligned}
& Y(x, t)=Y_{s}(x)+Y_{g}(x, t)+Y_{d}(x, t), \\
& U(\xi, t)=U_{s}(\xi)+U_{g}(\xi, t)+U_{d}(\xi, t) .
\end{aligned}
$$

Dynamic displacement satisfies the wave equation, continuity condition, equilibrium differential equation, and force boundary condition.

Static displacement of the bridge is as follows:

$$
\begin{aligned}
Y_{1 s}(x) & =\frac{\left[q\left(-5 L^{4}+6 L^{2} x^{2}-x^{4}\right)-2 F_{c}\left(2 L^{3}-x^{3}-3 x^{2} L\right)\right]}{24 E_{b} I_{b}}, \\
Y_{2 s}(x) & =\frac{\left[q\left(-5 L^{4}+6 L^{2} x^{2}-x^{4}\right)-2 F_{c}\left(2 L^{3}+x^{3}-3 x^{2} L\right)\right]}{24 E_{b} I_{b}}, \\
U(\xi) & =\frac{F_{c} \xi}{E_{r} A_{r}} .
\end{aligned}
$$

$Y_{1}$ and $Y_{2}$ are the left and right span displacements of main girder and $U$ is the pier displacement. $x$ is the distance from the middle of girder, and $\xi$ is the distance from the pier's base. $F_{c}$ is the axial pressure of the initial girder and the support. This can be expressed as

$$
F_{c}=\frac{-5 q L^{4}}{\left(24 E_{b} I_{b} H / E_{r} A_{r}\right)+\left(24 E_{b} I_{b} / K_{c}\right)+4 L^{3}} .
$$

The displacement of the rigid body of the bridge can be described as follows:

$$
Y_{1 g}(x, t)=Y_{2 g}(x, t)=U_{g}(x, t)=B(t) .
$$

The wave equations of girder $A B$ and pier $C D$ can be described as follows:

$$
\begin{array}{r}
O A: \frac{\partial^{2}\left(E_{b} I_{b} \partial^{2} Y_{1}(x, t) / \partial x^{2}\right)}{\partial x^{2}}+\rho A_{b} \frac{\partial^{2} Y_{1}(x, t)}{\partial t^{2}}+q=0, \\
O B: \frac{\partial^{2}\left(E_{b} I_{b} \partial^{2} Y_{1}(x, t) / \partial x^{2}\right)}{\partial x^{2}}+\rho A_{b} \frac{\partial^{2} Y_{1}(x, t)}{\partial t^{2}}+q=0, \\
C D: E_{r} A_{r} \frac{\partial^{2} U(\xi, t)}{\partial^{2} \xi}-\rho A_{r} \frac{\partial^{2} U(\xi, t)}{\partial t^{2}}=0 .
\end{array}
$$




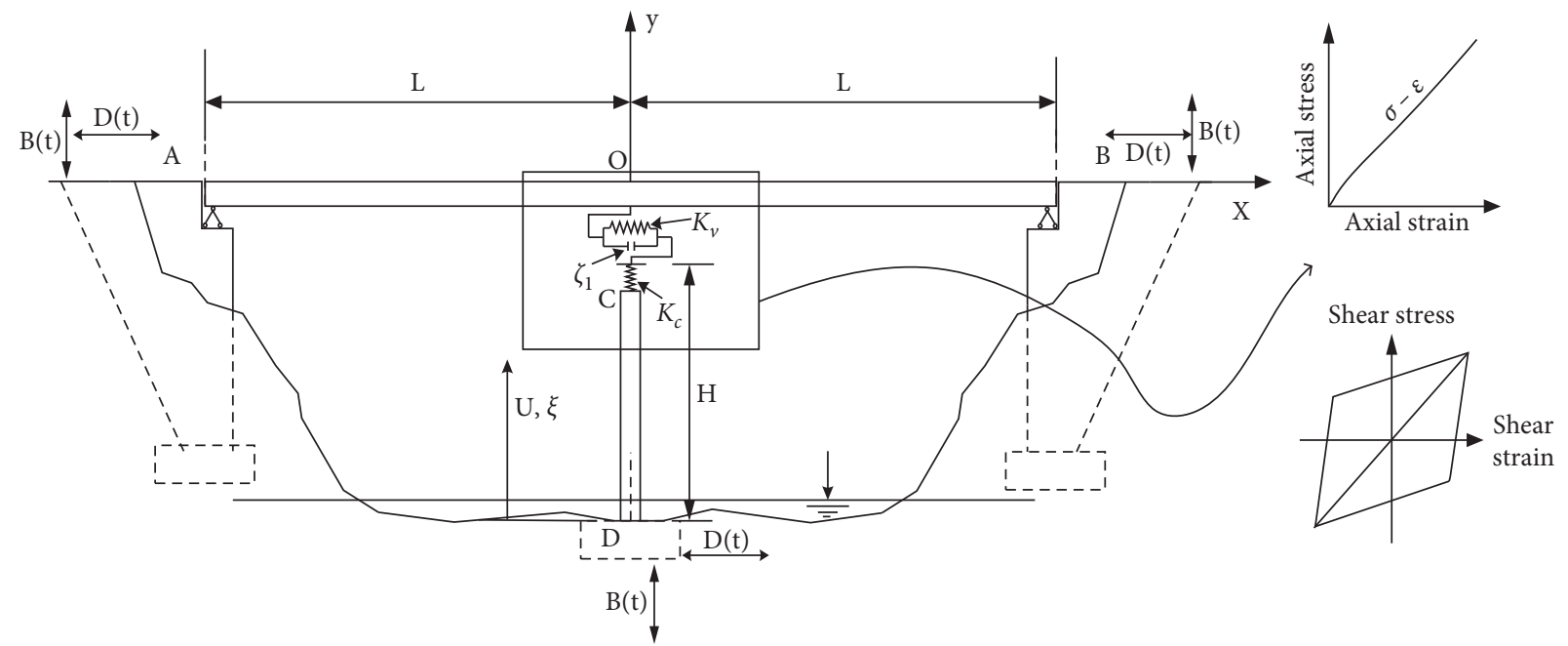

Figure 1: Model of a double-span continuous beam bridge.

In these equations, $Y_{1}(x, t), Y_{2}(x, t)$ is the deflection of the main beam; $U(\xi, t)$ is the axial displacement of pier.

The dynamic displacement part of the structure, which can be expanded as an infinite series of wave mode products:

$$
\begin{aligned}
Y_{1 d}(x, t) & =\sum_{n=1}^{\infty} \varphi_{n b 1}(x) q_{n}(t), \\
Y_{2 d}(x, t) & =\sum_{n=1}^{\infty} \varphi_{n b 2}(x) q_{n}(t), \\
U_{d}(\xi, t) & =\sum_{n=1}^{\infty} \varphi_{n r}(\xi) q_{n}(t),
\end{aligned}
$$

where $\varphi_{n b 1}, \varphi_{n b 2}$ is the bending wave function of the girder, $\varphi_{n r}$ is the longitudinal wave function, and $q_{n}(t)$ is the time function.

The wave model function was solved by the characteristic equations. The characteristic equations of the main girder and pier were as follows:

$$
\begin{gathered}
O A: a^{2} \varphi_{n b 1}^{(4)}(x)-\omega_{n}^{2} \varphi_{n b 1}(x)=0, \\
O B: a^{2} \varphi_{n b 2}^{(4)}(x)-\omega_{n}^{2} \varphi_{n b 2}(x)=0, \\
C D: c^{2} \varphi_{n r}^{(2)}(\xi)+\omega_{n}^{2} \varphi_{n r}(\xi)=0,
\end{gathered}
$$

where $\omega_{n}(n=1,2,3, \ldots)$ is the natural frequency of the bridge structure, $a=\sqrt{E_{b} I_{b} / \rho A_{b}}$ is the coefficient related to the beam flexural wave speed, and $c=\sqrt{E_{r} / \rho}$ is the rod phase speed.

Flexural wave modes of the main girder and the longitudinal wave of the pier can be described as

$$
\begin{aligned}
\varphi_{n b 1}(x)= & A_{1} \sin k_{b n} x+B_{1} \cos k_{b n} x+C_{1} \sinh k_{b n} x \\
& +D_{1} \cosh k_{b n} x, \\
\varphi_{n b 2}(x)= & A_{2} \sin k_{b n} x+B_{2} \cos k_{b n} x+C_{2} \sinh k_{b n} x \\
& +D_{2} \cosh k_{b n} x, \\
\varphi_{n r}= & E \sin k_{r n} \xi+F \cos k_{r n} \xi,
\end{aligned}
$$

where $k_{b n}$ and $k_{r n}$ are the wave numbers of flexural wave and longitudinal wave, respectively. $A_{1}, B_{1}, C_{1}, D_{1}, A_{2}, B_{2}, C_{2}, D_{2}, E$, and $F$ are the coefficients of the flexural wave and the longitudinal wave.

By introducing boundary conditions and continuity conditions, the wave functions of the bridge structure can be obtained as follows:

$$
\begin{aligned}
& \varphi_{n b 1}(x)=M_{n} A_{n}\left(-\frac{\sin k_{b n}(x+L)}{\cos k_{b n} L}+\frac{\sinh k_{b n}(x+L)}{\cosh k_{b n} L}\right), \\
& \varphi_{n b 2}(x)=M_{n} A_{n}\left(\frac{\sin k_{b n}(x-L)}{\cos k_{b n} L}-\frac{\sinh k_{b n}(x-L)}{\cosh k_{b n} L}\right),
\end{aligned}
$$$$
\varphi_{n r}(\xi)=A_{n} \sin k_{r n} \xi
$$

Through the orthogonality condition, the time function $q_{n}(t)$ differential equation of the bridge structure can be obtained:

$$
\omega_{n}^{2} q_{n}(t)+2 \zeta \omega_{n} \dot{q}_{n}(t)+q_{n}(t)=\ddot{Q}_{n}(t)
$$

By Laplace transformation, $q_{n}(t)$ can be obtained as follows:

$$
q_{n}(t)=e^{-\zeta_{2} \omega_{n} t}\left(q_{n}(0) \cos \omega_{d} t+\frac{\dot{q}_{n}(0)+\zeta_{2} \omega_{n} q_{n}(0)}{\omega_{d}} \sin \omega_{d} t\right)+\frac{1}{\omega_{d}} \int_{0}^{t} e^{-\zeta_{2} \omega_{n} \tau} \ddot{Q}_{n}(\tau) \sin \left(\omega_{d}(t-\tau)\right) \mathrm{d} \tau,
$$


where

$$
\begin{aligned}
q_{n}(0)= & \int_{-L}^{0} \rho A_{b} \varphi_{n b 1}(x) Y_{10}(x) \mathrm{d} x+\int_{0}^{L} \rho A_{b} \varphi_{n b 2}(x) Y_{20}(x) \mathrm{d} x \\
& +\int_{0}^{H} \rho A_{r} \varphi_{n r}(\xi) U_{0}(\xi) \mathrm{d} \xi+Q_{n}(0), \\
\dot{q}_{n}(0)= & \int_{-L}^{0} \rho A_{b} \varphi_{n b 1}(x) \dot{Y}_{10}(x) \mathrm{d} x+\int_{0}^{L} \rho A_{b} \varphi_{n b 2}(x) \dot{Y}_{20}(x) \mathrm{d} x \\
& +\int_{0}^{H} \rho A_{r} \varphi_{n r}(\xi) U_{0}(\xi) \mathrm{d} \xi+\dot{Q}_{n}(0) .
\end{aligned}
$$

2.2. Corresponding Theoretical Solution of Bridge's Vertical Separation Stage Displacement. During the separation process, the beam and the rod do not interact and move at their own characteristic frequencies of $\omega_{n b}$ and $\omega_{n r}$, respectively.

The vertical static displacement and rigid displacement of the bridge structure are as follows:

$$
\begin{aligned}
\bar{Y}_{s}(x) & =\frac{q\left(-5 L^{4}+6 L^{2} x^{2}-x^{4}\right)}{24 E_{b} I_{b}}, \\
\bar{U}_{s}(\xi) & =0, \\
\bar{Y}_{g}(x, t) & =\bar{U}_{g}(\xi, t)=B(t) .
\end{aligned}
$$

The wave equations of girder $A B$ and pier $C D$ can be described as follows:

$$
\begin{array}{r}
A B: \frac{\partial^{2}\left(E_{b} I_{b} \partial^{2} \bar{Y}(x, t) / \partial x^{2}\right)}{\partial x^{2}}+\rho A_{b} \frac{\partial^{2} \bar{Y}(x, t)}{\partial t^{2}}+q=0, \\
C D: E_{r} A_{r} \frac{\partial^{2} \bar{U}(\xi, t)}{\partial^{2} \xi}-\rho A_{r} \frac{\partial^{2} \bar{U}(\xi, t)}{\partial t^{2}}=0 .
\end{array}
$$

The wave functions of the bridge structure can be obtained as follows:

$$
\begin{aligned}
& \bar{\varphi}_{n b}(x)=A_{n b} \sin \bar{k}_{b n}(x+L), \\
& \bar{\varphi}_{n r}(\xi)=A_{n r} \sin \bar{k}_{r n} \xi .
\end{aligned}
$$

For the main girder and pier, the wavenumber is

$$
\begin{aligned}
& \bar{k}_{b n}=\sqrt{\frac{\omega_{b n}}{a}}=\frac{n \pi}{2 L}, \\
& \bar{k}_{r n}=\frac{\omega_{r n}}{c}=\frac{(2 n-1) \pi}{2 H} .
\end{aligned}
$$

Based on the orthogonality of the wave mode function, the coefficient can be obtained as

$$
\begin{aligned}
& A_{n b}=\frac{1}{\sqrt{\rho A_{b} L}}, \\
& A_{n r}=\frac{2}{\sqrt{\rho A_{r} H}} .
\end{aligned}
$$

If the separation contact phenomenon occurs many times, it can be assumed that $t^{*}=t-t_{2 k}$ is the time variable of the $k$ th collision, and $t^{*}=t-t_{2 k+1}$ is the time variable of the $k$ th separation.

In the $k$ th separation process, the dynamic displacement responses of the main girder and pier are as follows:

$$
\begin{aligned}
q_{n b}\left(t^{*}\right)= & e^{-\zeta_{2} \omega_{b 1} t^{*}}\left(q_{1 b}\left(t_{2 k+1}^{+}\right) \cos \omega_{b 1} t^{*}+\frac{\dot{q}_{n}\left(t_{2 k+1}^{-}\right)+\zeta_{2} \omega_{b 1} q_{n b}(0)}{\omega_{b 1}} \sin \omega_{b 1} t^{*}\right) \\
& +\frac{1}{\omega_{b d}} \int_{t_{2 k+1}^{*}}^{t^{*}} e^{-\zeta_{2} \omega_{b n} \tau}(\tau) \sin \left(\omega_{b d}\left(t^{*}-\tau\right)\right) \mathrm{d} \tau, \\
q_{n r}\left(t^{*}\right)= & e^{-\zeta_{2} \omega_{r 1} t^{*}}\left(q_{1 r}\left(t_{2 k+1}^{+}\right) \cos \omega_{b 1} t^{*}+\frac{\dot{q}_{n}\left(t_{2 k+1}^{-}\right)+\zeta_{2} \omega_{r 1} q_{n r}(0)}{\omega_{r 1}} \sin \omega_{r 1} t^{*}\right) \\
& +\frac{1}{\omega_{r d}} \int_{t_{2 k+1}^{+}}^{t^{*}} e^{-\zeta_{2} \omega_{r n} \tau}(\tau) \sin \left(\omega_{r d}\left(t^{*}-\tau\right)\right) \mathrm{d} \tau .
\end{aligned}
$$


The initial displacement and velocity of the girder and pier structure are considered only by the first mode. By viewing the residual rate and deformation of the last process, the contact separation process is solved continuously.

\subsection{Corresponding Theoretical Solution of Bridge's Vertical} Collision Stage Displacement. When the relative displacement between the girder and pier is less than zero, it is considered that the girder and the pier are in contact again. At the moment of collision contact, the overall frequency of the bridge cannot be calculated. The use of resonance frequency calculation will produce large dispersion, and it is difficult to ensure the convergence of the calculation results. In the process of vertical impact process, the dynamic deformation after contact collision can be divided into the impact force deformation $X_{F}$ and the dynamic wave deformation $X_{z}$. The indirect mode superposition method [26] was used to calculate the structural displacement under the impact force. Initial contact time was calculated as $Y_{s}+Y_{d}=U_{s}+U_{d}=0$. In the subsequent vertical collision process, the main beam and the bridge pier have no vertical contact force at the initial moment. And the static displacement of the girder and the pier is zero. It can be concluded that the dynamic displacement of the bridge at the initial moment is

$$
Y_{1 d}\left(0, t_{2 k}^{+}\right)=Y_{2 d}\left(0, t_{2 k}^{+}\right)=U_{d}\left(0, t_{2 k}^{+}\right)=0 .
$$

The collision displacements of the structure are

$$
\begin{gathered}
Y_{F}=\frac{\sum_{i=1}^{\infty} \bar{\varphi}_{n b}(0) \dot{q}_{b n}\left(t_{2 k}^{-}\right)}{\omega_{n b}} \sin \omega_{n b} t-\sum_{n=1}^{\infty} \bar{\varphi}_{n b}(x) \int_{t_{2 k}}^{t^{*}} Q_{n b} h_{n b} \mathrm{~d} \tau, \\
U_{F}=\frac{\sum_{i=1}^{\infty} \bar{\varphi}_{n r}(0) \dot{q}_{r n}\left(t_{2 k}^{-}\right)}{\omega_{n r}} \sin \omega_{n r} t+\sum_{n=1}^{\infty} \bar{\varphi}_{n r}(\xi) \int_{t_{2 k}}^{t^{*}} Q_{n r} h_{n r} \mathrm{~d} \tau,
\end{gathered}
$$

where $Q_{n b}=F_{p} \bar{\varphi}_{n b}\left(x_{0}\right), Q_{n r}=F_{p} \bar{\varphi}_{n r}\left(\xi_{0}\right)$ is the generalized collision force. $x_{0}$ and $\xi_{0}$ are the coordinates of the collision point of the main beam and pier, respectively. $F_{p}$ is the impact force. The positive and negative signs in equation (20) denote the relationship between force and displacement direction, respectively.

$$
\begin{aligned}
& h_{n b}=\frac{1}{M_{n b} \omega_{n b}} \sin \omega_{n b}(t-\tau), \\
& h_{n r}=\frac{1}{M_{n r} \omega_{n r}} \sin \omega_{n r}(t-\tau),
\end{aligned}
$$

where $M_{n b}$ and $M_{n r}$ are modal masses.

$$
\begin{aligned}
& M_{n b}=\int_{-L}^{L} \rho A \bar{\varphi}_{n b}^{2}(x) \mathrm{d} x, \\
& M_{n r}=\int_{0}^{H} \rho A_{r} \bar{\varphi}_{n r}^{2}(\xi) \mathrm{d} \xi .
\end{aligned}
$$

At the impact contact stage, the displacements of the girder and the pier differ. The impact force $F_{p}=0$ when the girder and pier are separated, and the collision force $F_{p}>0$. At the impact point, the displacement response is

$$
Y_{F}(0, t)-U_{F}(H, t)=\frac{F_{p}(t)}{K_{c}} .
$$

By introducing equation (20) in equation (23), the vertical load $F_{p}$ and the collision contact part of bridge structure displacement $Y_{F}, U_{F}$ can be calculated by using the step-by-step integration method.

The partial time function of dynamic deformation is as follows:

$$
q_{n}(t)=\frac{1}{\omega_{n}} \int_{t_{2 k}}^{t^{*}} \ddot{Q}_{n}(\tau) \sin \left(\omega_{n}(t-\tau)\right) \mathrm{d} \tau .
$$

The dynamic deformation of the bridge can be expressed as follows:

$$
\begin{aligned}
Y_{d 1} & =\sum_{n=1}^{\infty} \varphi_{n b 1}(x) q_{n}(t), \\
Y_{d 2} & =\sum_{n=1}^{\infty} \varphi_{n b 2}(x) q_{n}(t), \\
U_{d} & =\sum_{n=1}^{\infty} \varphi_{n r}(\xi) q_{n}(t) .
\end{aligned}
$$

\section{Calculation of the Bridge's Longitudinal Displacement Response}

Referring to the process of solving the vertical displacement response of the bridge, the wave mode equations of the girder and pier in the longitudinal direction can be obtained as follows:

$$
\begin{aligned}
\bar{\varphi}_{n b}(x)= & A_{n b} \sin \bar{k}_{b n}(x+L), \\
\bar{\varphi}_{n r}(\xi)= & A_{n r}\left(\cosh \bar{k}_{r n} \xi-\cos \bar{k}_{r n} \xi\right) \\
& +M_{3}\left(\sinh \bar{k}_{r n} \xi-\sin \bar{k}_{r n} \xi\right) .
\end{aligned}
$$

Considering the bearing damping, the time function of the bridge displacement response is

$$
\begin{aligned}
q_{n}\left(t^{*}\right)= & e^{-\left(\zeta_{1}+\zeta_{2}\right) \omega_{n} t^{*}}\left(q_{n}(0) \cos \omega_{d} t^{*}+\frac{\dot{q}_{n}(0)+q_{n}(0) \omega_{n}\left(\zeta_{1}+\zeta_{2}\right)}{\omega_{d}} \sin \omega_{d} t^{*}\right) 1 \\
& +\frac{1}{\omega_{d}} \int_{0}^{t^{*}}(\tau) e^{-\left(\zeta_{1}+\zeta_{2}\right) \omega_{n}(t-\tau)} \sin \omega_{d}\left(t^{*}-\tau\right) \mathrm{d} \tau,
\end{aligned}
$$


where $\omega_{d}=\sqrt{\left[1-\left(\zeta_{1}+\zeta_{2}\right)^{2}\right]} \omega_{n}$.

The time function of the girder and pier is consistent with equation (23). The calculation process of the longitudinal displacement response of the bridge in the collision process is the same as the vertical calculation process, except that $\zeta_{2}$ in equations (21) and (26) is changed to $\zeta_{1+2}$.

\section{Bridge Model and Vertical Seismic Response Spectrum}

4.1. Bridge Model. We used a double-span box type continuous girder bridge for analysis. The piers are composed of two circular concrete columns with spiral stirrups and longitudinal bars. Figure 2 shows the longitudinal section of the bridge and the reinforcement of the pier.

In the process of calculation, in order to facilitate the analysis, the bridge model reference code is equivalent [27]. According to the specification, the equivalent cross-sectional area of the bridge pier is $A_{r}=A_{r c}+\left(\alpha_{y}-1\right) A_{r y}$, the equivalent Young's modulus of bridge pier is $E_{r}=\left(E_{r c} A_{r c}+E_{r y} A_{r y}\right) /\left(A_{r c}+A_{r y}\right)$, and the equivalent moment of inertia of bridge pier is $I_{r}=I_{r c}+I_{r y}$. The equivalent section area of main beam is $A_{b}=A_{b c}+\left(\alpha_{y}-1\right) A_{b y}+\left(\alpha_{p}-1\right) A_{b p} ; \quad$ the equivalent Young's modulus of the main beam is $E_{b}=\left(E_{b c} A_{b c}+E_{b y} A_{b y}+E_{b p} A_{b p}\right) /\left(A_{b c}+A_{b y}+A_{b p}\right)$. The equivalent section moment of inertia of the main beam is $I_{b}=I_{b c}+I_{b y}+I_{b p}$. The round lead rubber bearing is used between the main girder and the piers.

Based on a large number of theoretical and experimental studies, the hysteresis curve of the rubber bearing was elongated, and the vertical stiffness was approximately set to a constant. For the convenience of calculation, this article assumed that the rubber bearing stiffness was $K_{c}=2.4 \times 10^{9} \mathrm{~N} / \mathrm{m}$. In the horizontal direction, the high damping rubber bearing was assumed to be a spring damping model, the shear stiffness of the rubber bearing was $K_{v}=2.4 \times 10^{6} \mathrm{~N} / \mathrm{m}$, and the damping was taken as $\zeta_{1}=20 \%$. The damping coefficient of the main girder and pier was set to $\zeta_{2}=2 \%$.

Figure 2 shows the reinforcement details and crosssectional dimensions of the bridge. The bearing adopts a high damping rubber bearing. In the process of calculation, in order to facilitate the analysis, the bridge model reference code is equivalent [27].

4.2. Vertical Seismic Response Spectrum. The bridge was located in an area with a seismic intensity of $8^{0}$; the bridge was subjected to a rare earthquake. The reference peak value of the horizontal seismic acceleration was $510 \mathrm{gal}\left(5.1 \mathrm{~m} / \mathrm{s}^{2}\right)$. The venue is classified as Class $I_{1}$. The values of horizontal seismic acceleration under different seismic excitation periods are shown in the specification [20]. The selection of the characteristic value of the vertical seismic response spectrum was given in [20], and the distances from the epicenter were $3 \mathrm{~km}, 10 \mathrm{~km}$, and $20 \mathrm{~km}$, respectively:

$$
\lambda=\frac{V}{H}= \begin{cases}\alpha, & T<0.1, \\ \alpha-\beta(T-0.1), & 0.1 \leq T<0.3, \\ 0.5, & T \geq 0.3,\end{cases}
$$

where $\lambda$ is the ratio of the vertical and horizontal seismic excitation amplitudes. $T$ is the vertical seismic excitation period, $\alpha$ is the peak value of $V / H$, and $\beta$ is the linear attenuation coefficient. When the epicenter distance is $3 \mathrm{~km}$, $10 \mathrm{~km}$, and $20 \mathrm{~km}, \alpha=1.5,1.4$, and $1.3 ; \beta=5,4$, and 3 . Complex seismic waves can be obtained by the superposition of harmonic components of each order by the Fourier expansion method. By calculating the excitation of a single harmonic component, the seismic excitation response of bridge structure in full frequency state can be obtained by superposition method. Therefore, for the sake of simplicity, this paper used the single harmonic motion instead of seismic excitation, and the acceleration peak value was the seismic excitation acceleration peak value.

\section{Numerical Results}

5.1. Effect of Near-Fault Vertical Seismic Acceleration on the Structure. Figure 3 shows the flowchart of vertical seismic calculation, and the total computation time was $2 \mathrm{~s}$. By recording the time of each separation and recontact in the vertical calculation, and substituting it into the longitudinal seismic calculation, the longitudinal displacement response of the bridge considering the separation condition was obtained.

Figure 4 shows the seismic response of piers at three pier heights. When the pier height $H=5 \mathrm{~m}$, the first separation of the structure occurred at $0.412 \mathrm{~s}$, and the structure was separated for 9 times in the calculation time. The maximum impact force in the vertical direction was $35.47 \mathrm{MN}$. When the pier height $H=10 \mathrm{~m}$, the first separation of the structure occurred at $0.445 \mathrm{~s}$, and the structure was separated for 8 times in the calculation time. The maximum impact force in the vertical direction was $34.85 M N$. When the pier height $H=15 \mathrm{~m}$, the first separation occurred at $0.625 \mathrm{~s}$, and the structure was separated for 6 times in the calculation time. The maximum impact force in the vertical direction was 30.94 MN. It can be seen that with the increase of pier height, the pier in the vertical direction shows greater flexibility. It reduced the separation probability and the vertical impact force. Therefore, when the pier height was lower, excessive vertical seismic acceleration was more likely to cause pier and girder separation and increased the vertical impact force.

In the longitudinal direction, when $H=5 \mathrm{~m}$, the maximum longitudinal relative displacement of pier and girder increased from $1.49 \mathrm{~mm}$ to $1.84 \mathrm{~mm}$ due to separation, increasing by $23.5 \%$. When $H=10 \mathrm{~m}$, the maximum value increased from $18.01 \mathrm{~mm}$ to $23.35 \mathrm{~mm}$, an increase of $29.7 \%$. When $H=15 \mathrm{~m}$, the maximum value increased from $12.43 \mathrm{~mm}$ to $51.45 \mathrm{~mm}$, an increase of $314 \%$. Although the short pier was easy to cause structural separation, the separation has little influence on the longitudinal 


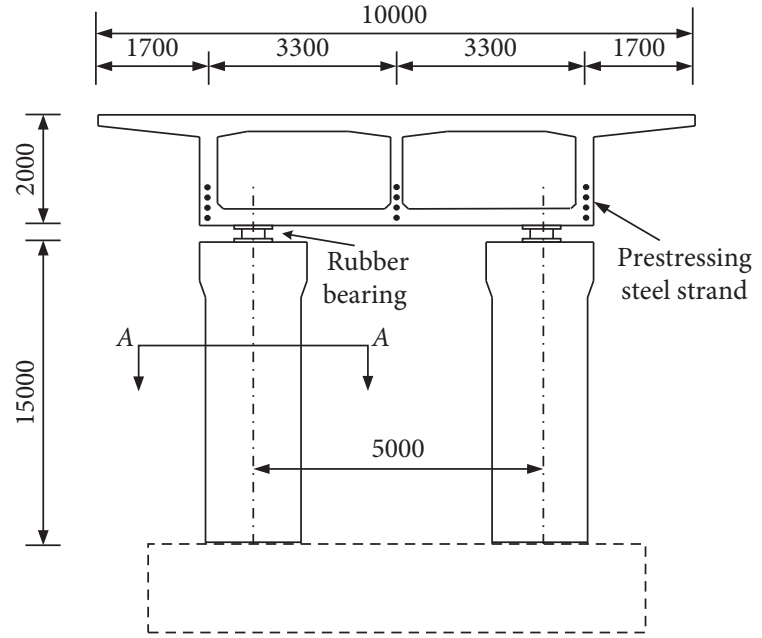

(a)

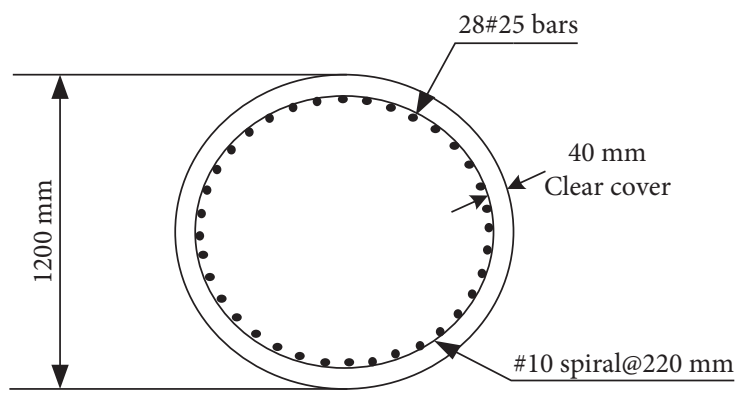

(b)

FIGURE 2: Interface models and dimensions of bridges. (a) Main girder cross section. (b) Cross section of piers.

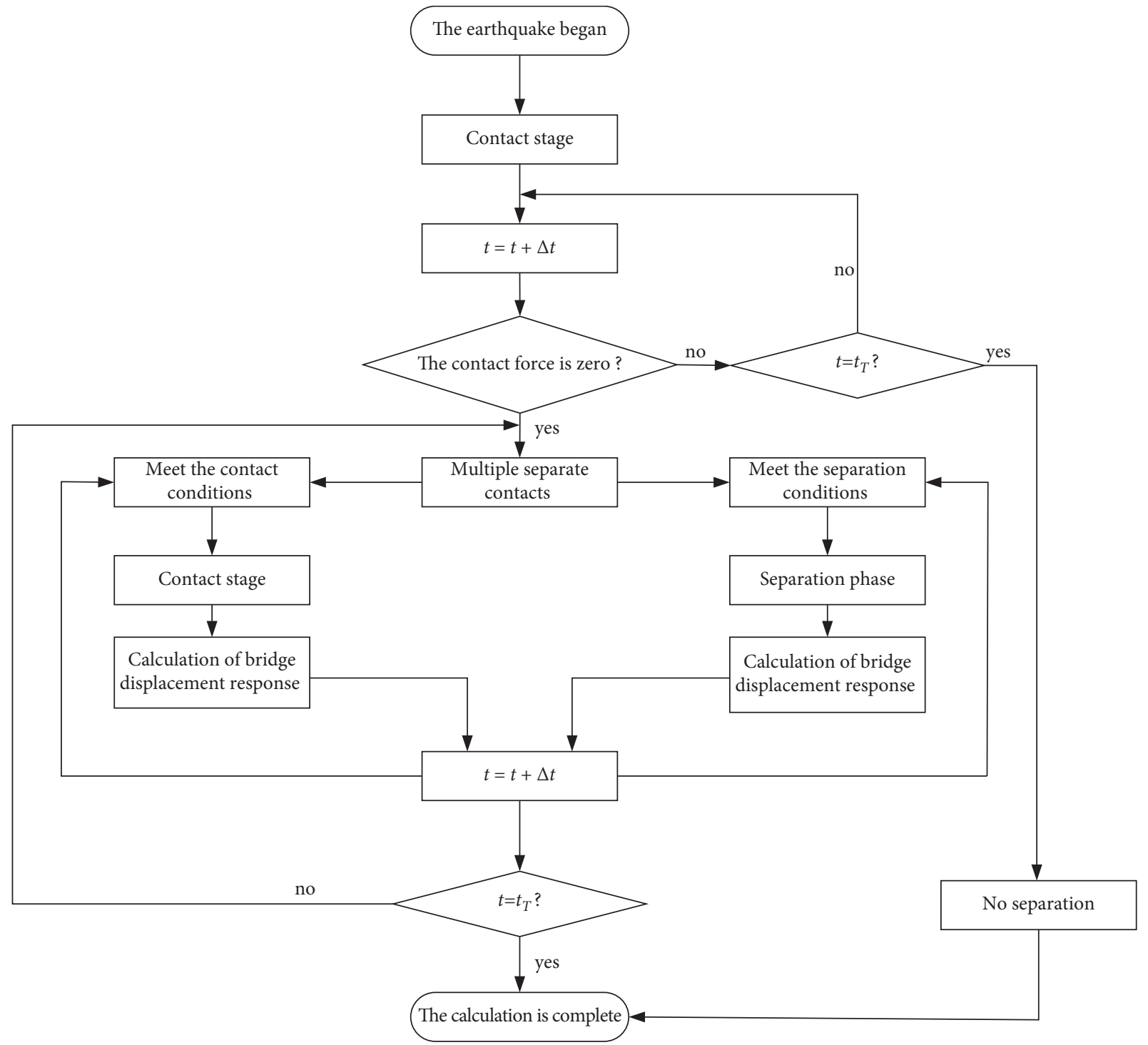

FIGURE 3: Flowchart of bridge vertical displacement calculation procedure. 


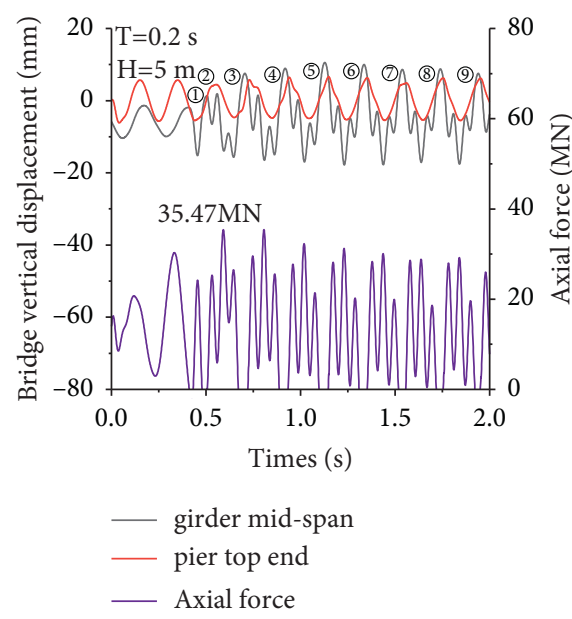

(a)
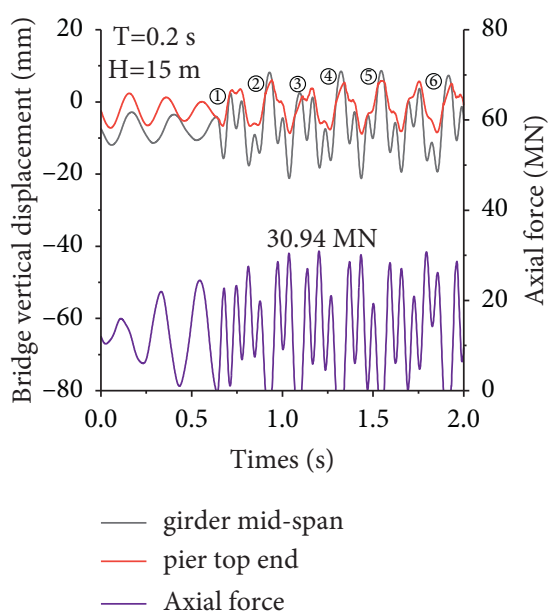

(c)

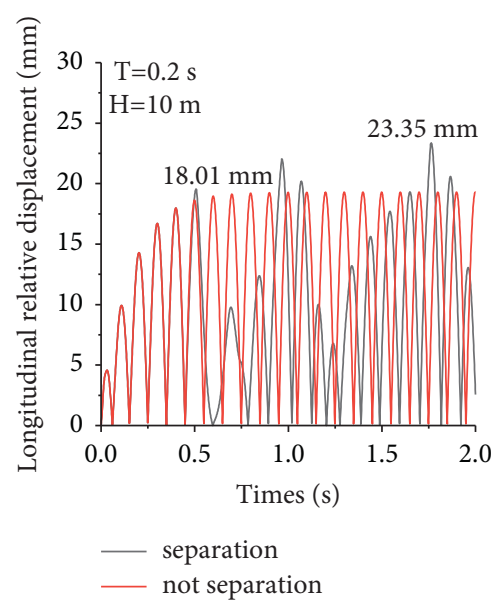

(e)

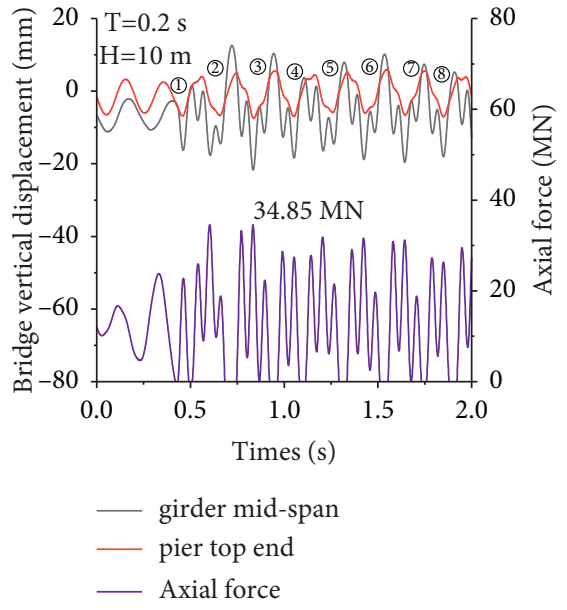

(b)

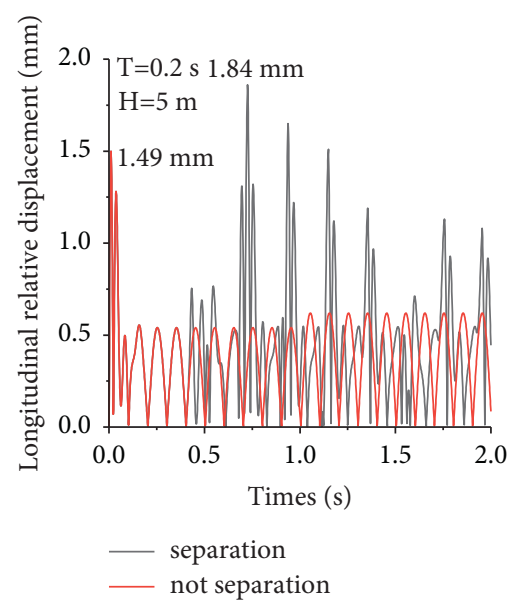

(d)

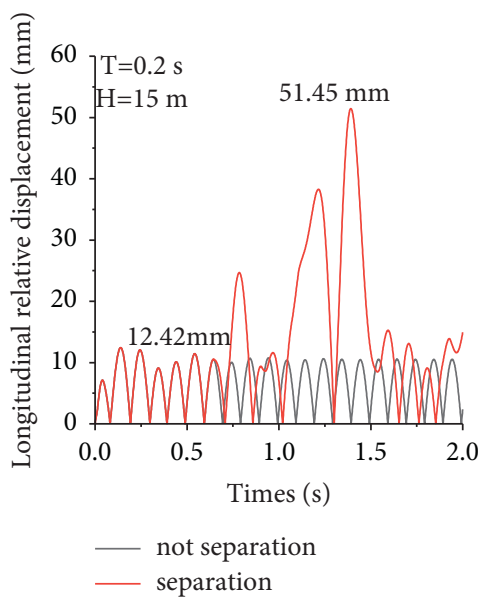

(f)

FIGURE 4: Bridge displacement response. (a) Vertical displacement when $H=5 \mathrm{~m}$; (b) relative displacement response when $H=10 \mathrm{~m}$; (c) vertical displacement when $H=15 \mathrm{~m}$; (d) relative displacement when $H=5 \mathrm{~m}$; (e) relative displacement response when $H=10 \mathrm{~m}$; (f) relative displacement when $H=15 \mathrm{~m}$.

displacement. Only when the longitudinal natural vibration period $T_{s}$ of the bridge is greater than the seismic excitation period $T$, the separation will greatly increase the longitudinal relative displacement of the pier and girder.
The change of longitudinal relative displacement of pier beam significantly affects the bending moment at the bottom of pier; the bending moment is composed of three forces. Figure 5 shows a simplified mechanical model. Those are 


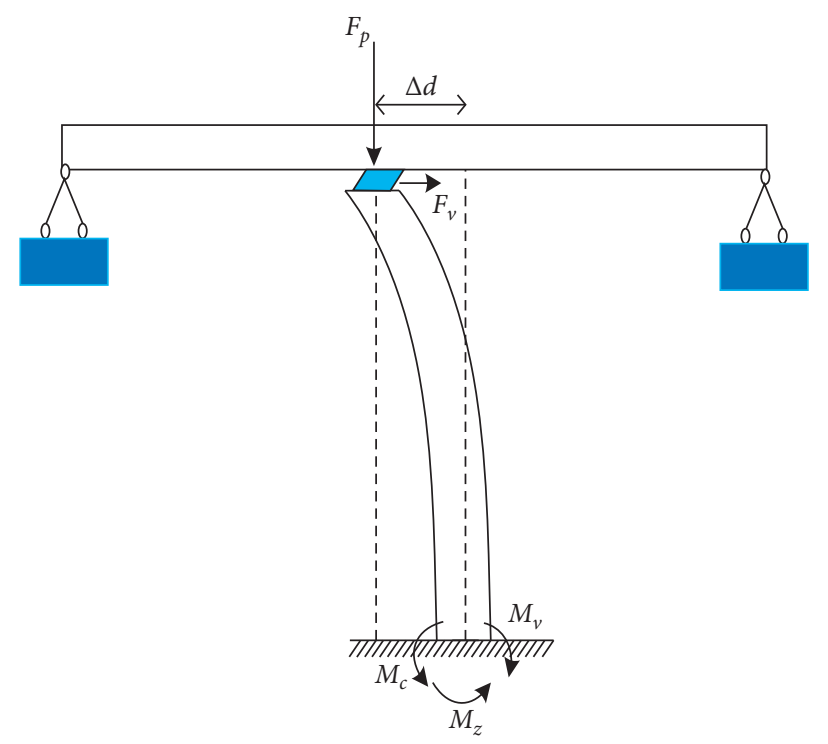

FIGURE 5: Schematic diagram of the bending moment at the bottom of the pier.

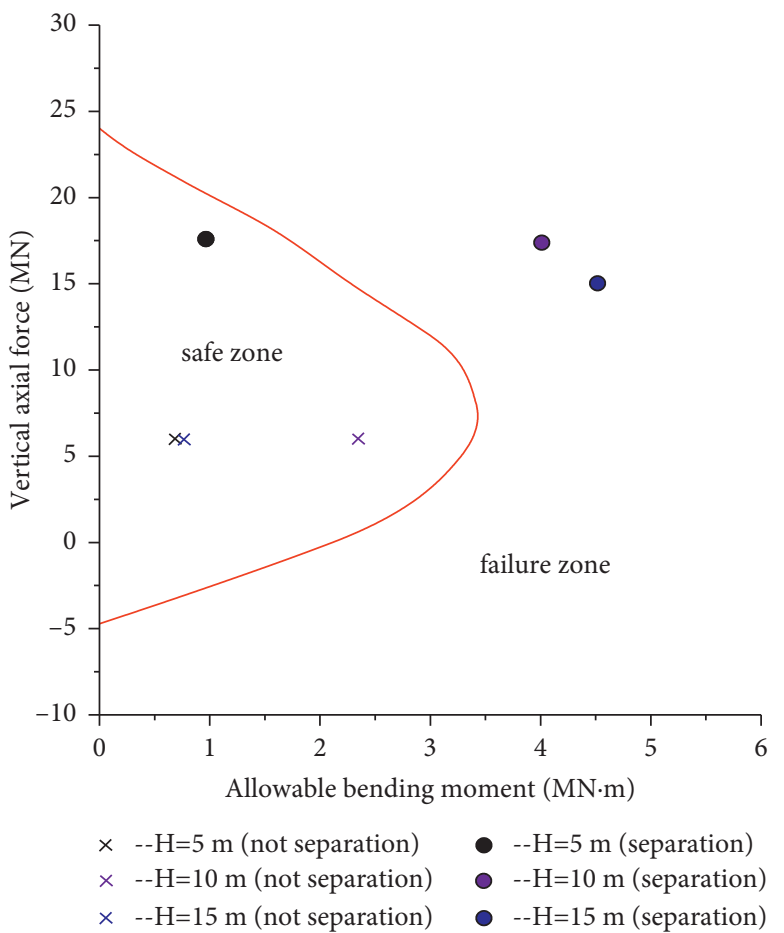

(a)

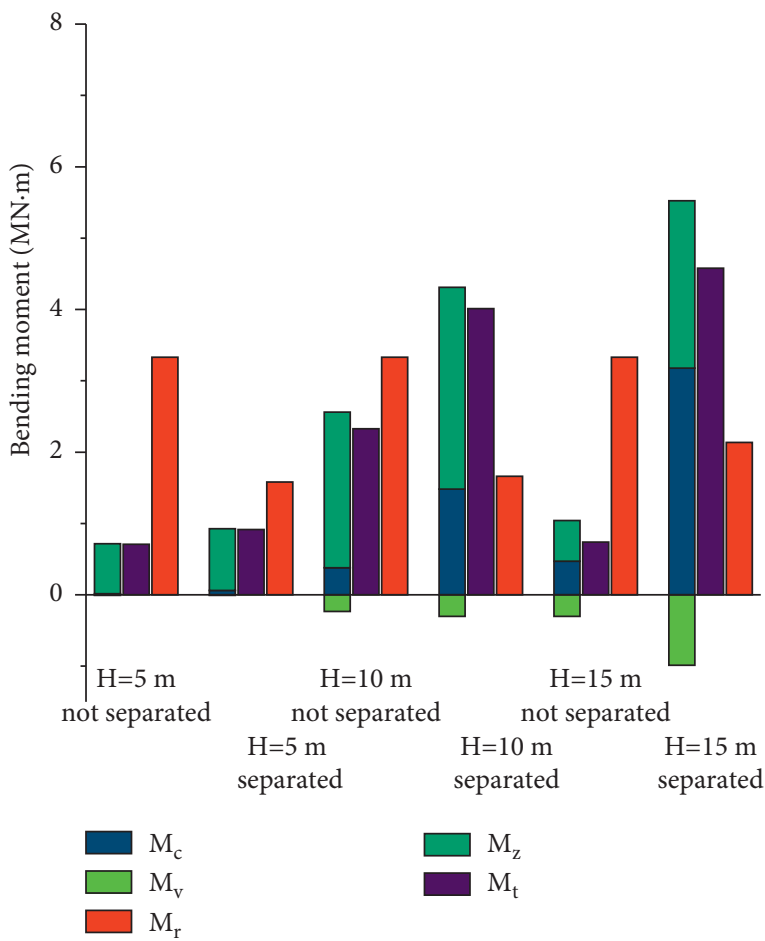

(b)

Figure 6: Bending moment at the base of the pier. (a) Total bending moment and an allowable bending moment. (b) Various bending moments.

bending moment $M_{z}$ produced by the forced resonance of bridge, bending moment $M_{p}$ produced by the vertical eccentric impact, and bending moment $M_{v}$ due to the bearing shear. During the calculation, the following assumptions are made: (1) the bearing had never been damaged, $F_{v}=K_{v} \times \Delta d$, and $\Delta d$ is equal to the longitudinal relative displacement of the main girder and pier; (2) when calculating the resonant bending moment of bridge pier, the elastic model is adopted for analysis, and the plastic effect is ignored; and (3) considering the worst case, the bending moment caused by eccentric impact can be calculated by $M_{c}=F_{\max } \times \eta \times \Delta L$, where $F_{\max }$ is the maximum vertical 


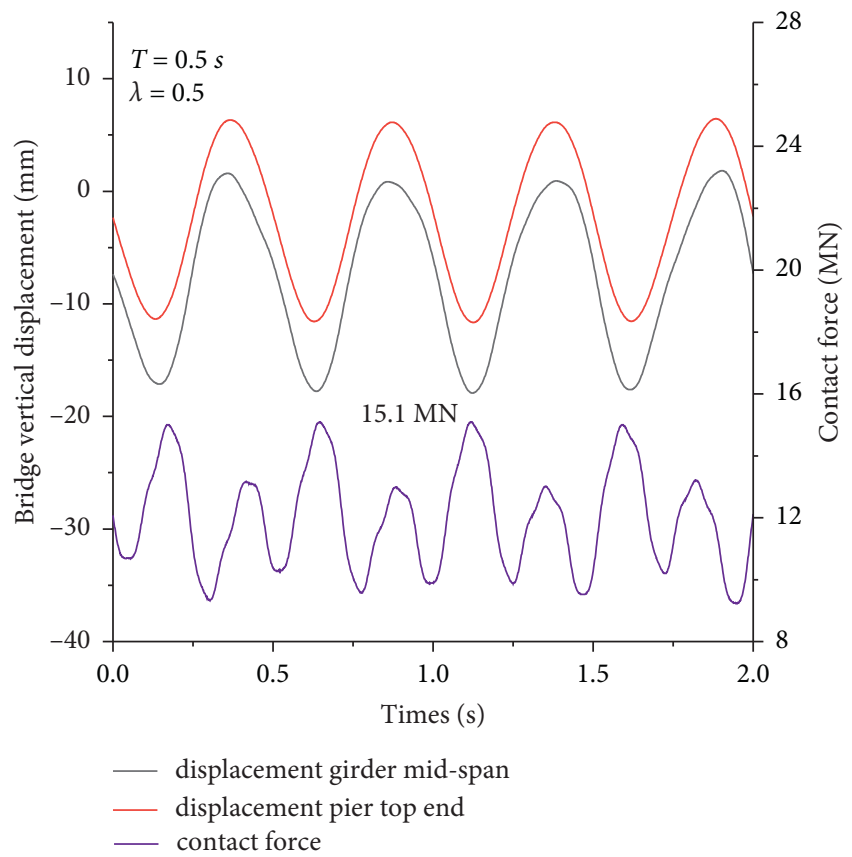

(a)

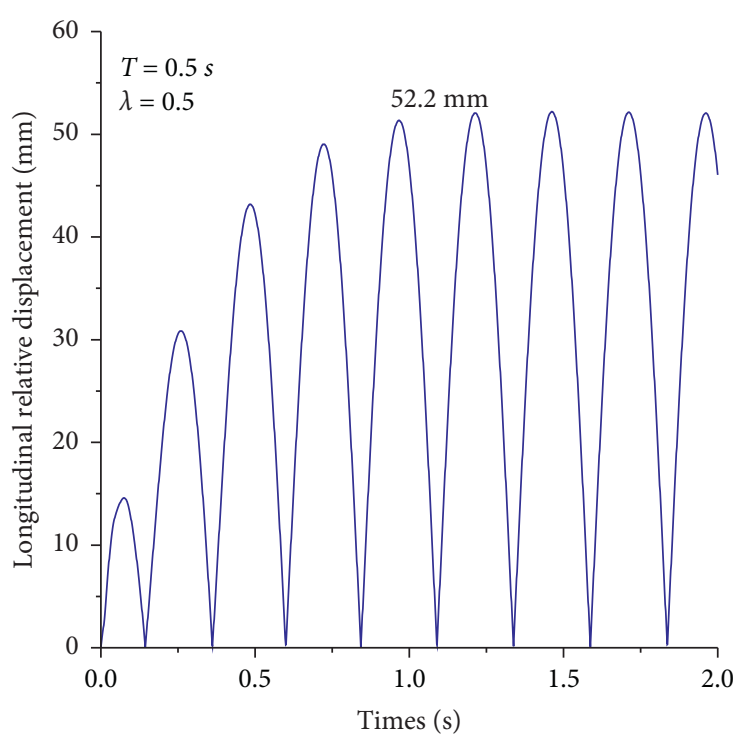

(b)

Figure 7: Displacement response of bridge when $T=0.5 \mathrm{~s}$. (a) Vertical displacement and force. (b) Longitudinal relative displacement.

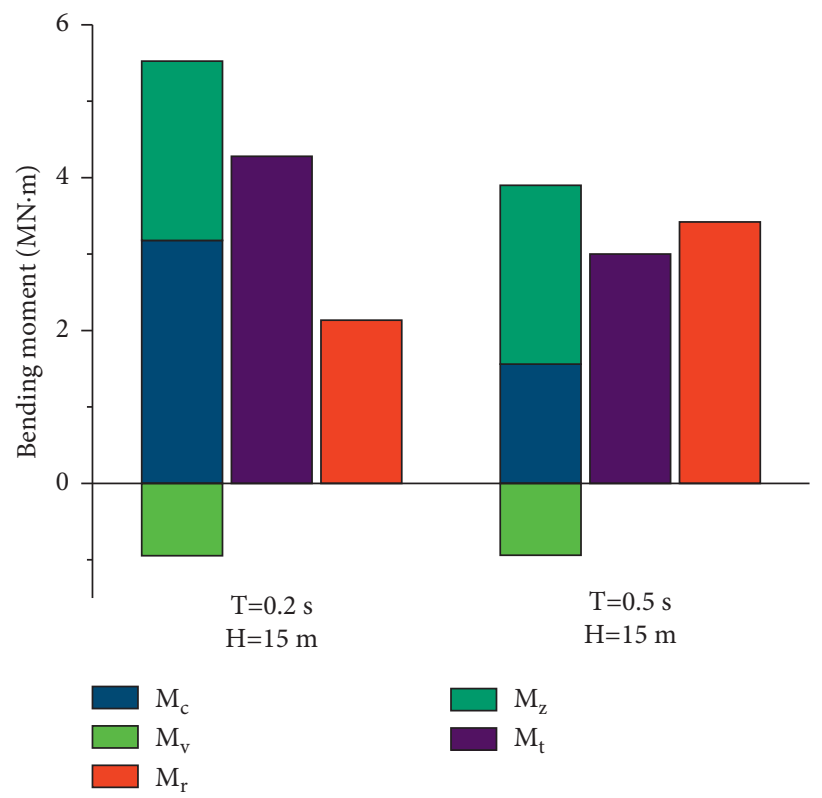

Figure 8: Bending moments of piers under different periods.

impact force, $\Delta L$ is the maximum longitudinal relative displacement, and $\eta$ is amplification coefficient of long axis instability condition

Figure 6 shows the various and total bending moments of piers with three heights. When the separation was ignored, the vertical contact force between the main girder and pier was calculated as the static contact force. When separation was considered, the vertical contact force was calculated as the maximum vertical impact force. When the separation was ignored, the pier of different heights was safety due to the energy dissipation of the damped rubber bearing. When $H=10 \mathrm{~m}$, the longitudinal excitation period $T_{s}$ of the bridge was close to the seismic excitation period $T$, and the higher resonance results in a significant increase in the bending moment at the base of the pier.

When considering the structure separation caused by large vertical accelerations under near-fault earthquake, the results were different. The vertical separation caused 


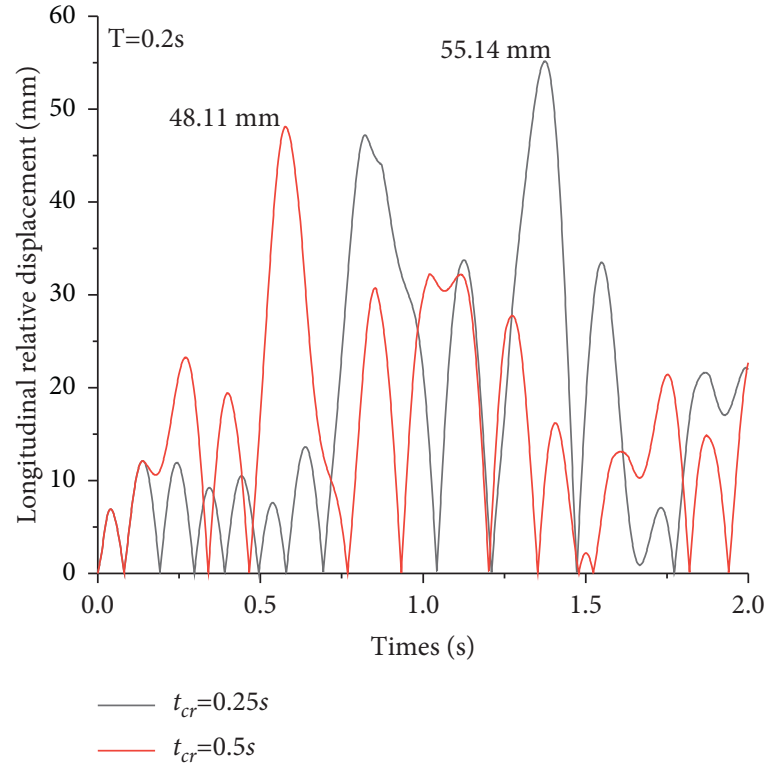

(a)

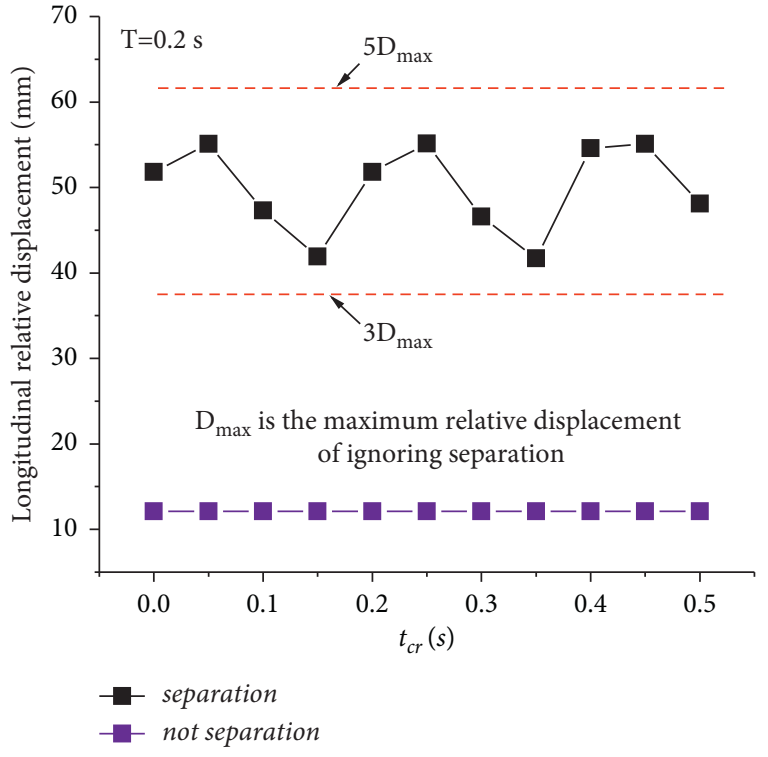

(b)

Figure 9: Longitudinal relative displacement of beam and pier at different periods. (a) $t_{c r}=0.25 \mathrm{~s}$ and $t_{c r}=0.5 \mathrm{~s}$. (b) Different arrival time difference.

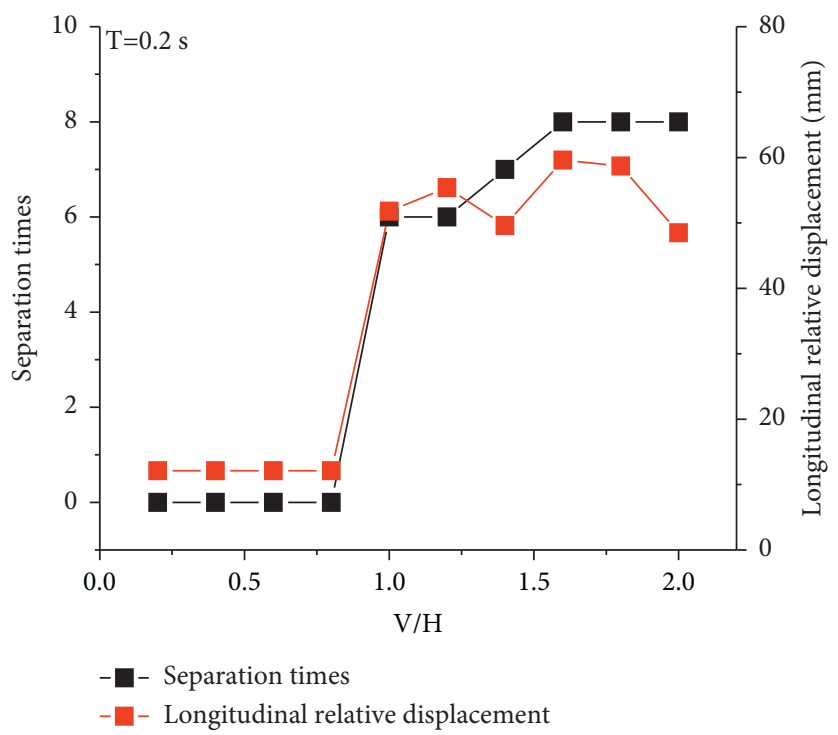

FIGURE 10: Separation times and maximum longitudinal relative displacements of main girder and pier at different $V / H$.

multiple collisions between the girder and pier, and the collision force was much higher than the static contact force. As a result, the allowable bending moment of piers decreases. Vertical separation also increased pier bending moment. Since the longitudinal relative displacement of the pier increased too much when $H=15 \mathrm{~m}$, the increased bending moment leaded to the bending damage of the pier. However, the longitudinal natural vibration period $T_{s}$ of bridge pier was far from the seismic excitation period $T$.

Figure 6(b) shows the changes of bending moments of piers with different heights under seismic excitation. When the pier height was $H=5 \mathrm{~m}$, the longitudinal relative displacement of pier and girder was low regardless of separation. The bending moment of piers is mainly due to bridge resonance. When the pier height was $H=10 \mathrm{~m}$, the longitudinal displacement response was greatly increased by resonance, but the longitudinal relative displacement was not affected by separation. The bending moment changes little due to vibration and bearing shear. The vertical impact force greatly increases the bending moment produced by the eccentric impact. When the height of pier $H=15 \mathrm{~m}$, the peak of the eccentric compression was greater due to significant increase of the longitudinal relative displacements of beam and pier. The separation caused the pier's base to change 


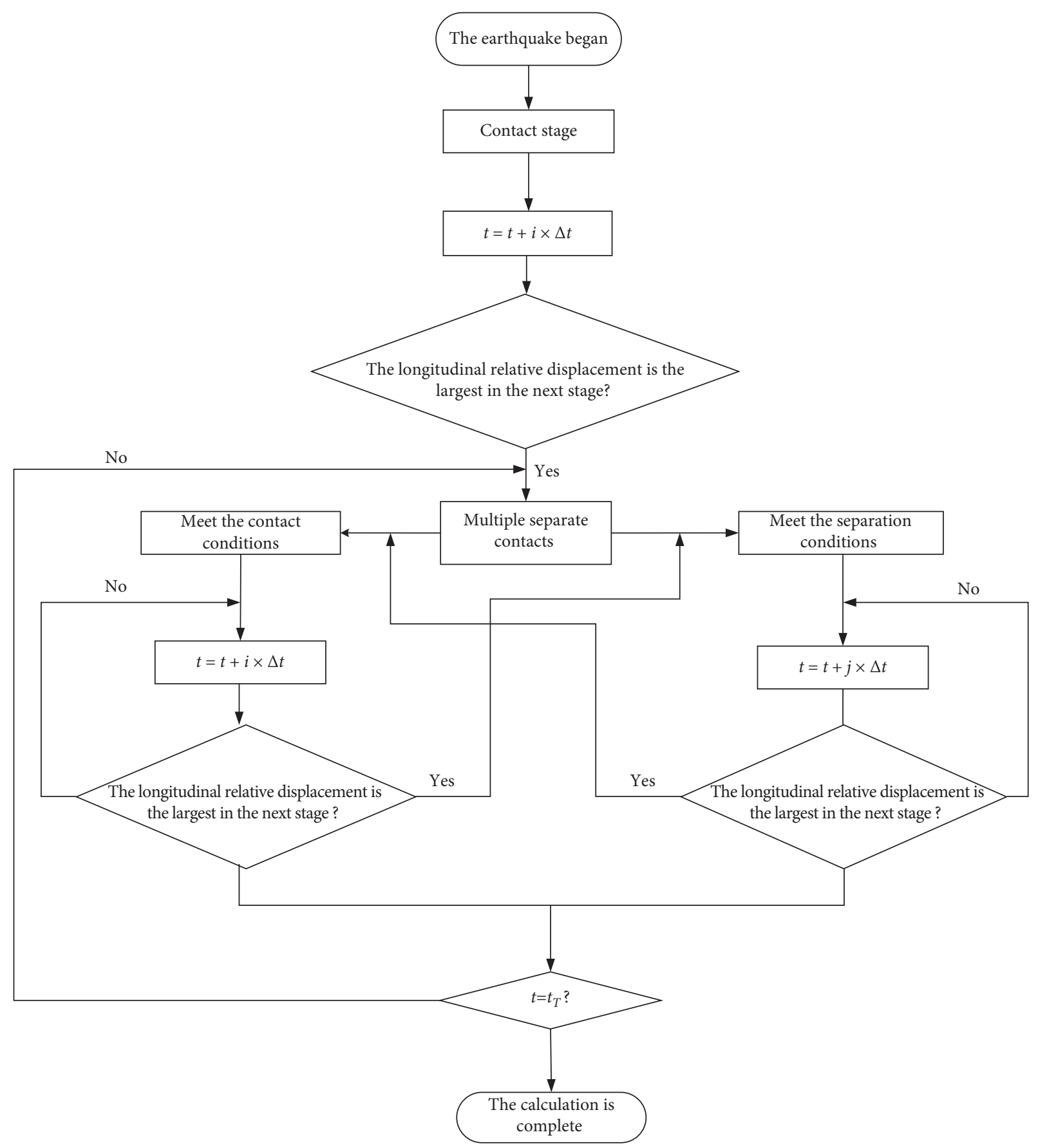

FIGURE 11: Flowchart of calculation program for maximum longitudinal displacement of bridge.

from the safe zone to the failure zone. For medium- and small-span bridges, the separation will significantly change the longitudinal displacement of the structure for high piers.

\subsection{Responses of High Pier Bridges under Different Excitation} Cycles. When the period of vertical seismic excitation is close to the period of natural vibration of the bridge, the bridge may be separated and the pier may be destroyed. However, only the case of $T \approx T_{v}$ was considered above. When $T \approx T_{s}$, resonance may cause damage to bridge pier. Figure 7 shows the vertical response of the bridge when
$H=15 \mathrm{~m}$. The seismic excitation period was far from the vertical natural vibration period, and no separation will occur. The maximum vertical contact force $F=15.1 \mathrm{MN}$, which was 1.25 times of the static contact force.

Figure 8 shows the variation of bending moments of bridge piers at $T=0.2 \mathrm{~s}$ and $T=0.5 \mathrm{~s}$. When $T=0.5 \mathrm{~s}$, the resonance causes a large longitudinal displacement of the bridge. The maximum longitudinal relative displacement that can be seen was very close to that at $T=0.2 \mathrm{~s}$. Therefore, there was little difference between $M_{z}$ and $M_{v}$ when $T=0.5 \mathrm{~s}$ and $T=0.2 \mathrm{~s}$. However, when $T=0.2 \mathrm{~s}$, the increase of vertical force caused by structural separation will improved 


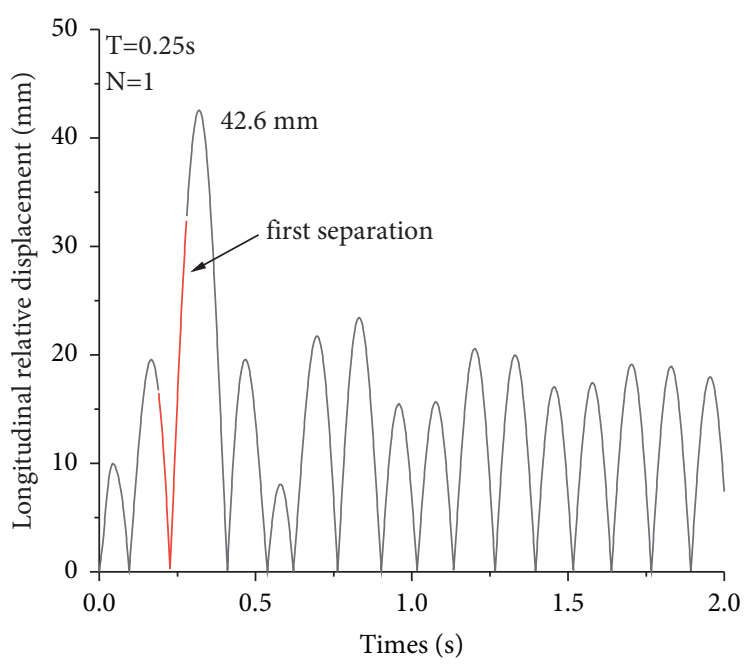

(a)

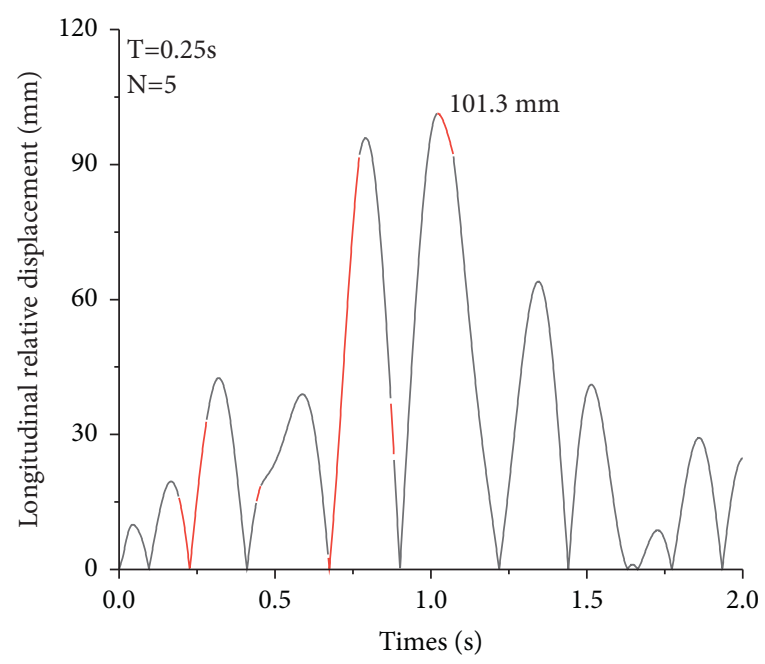

(b)

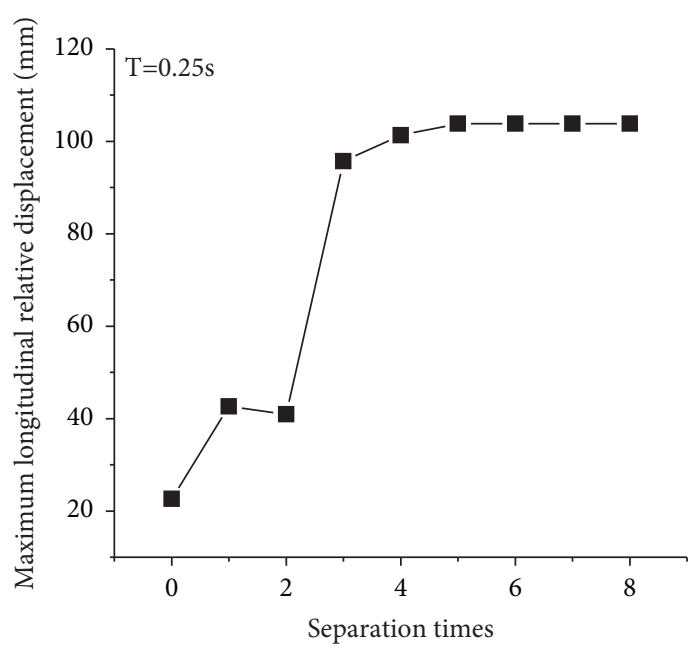

(c)

Figure 12: Maximum longitudinal relative displacement at different separation times. (a) $N=1$; (b) $N=5$; (c) different separation times.

the bending moment generated by eccentric compression, and the total bending moment of piers increased. In addition, higher vertical forces also reduced the allowable bending moment.

5.3. Effect of Seismic Wave Arrival Time Difference on Longitudinal Displacement. When the epicenter distance was different, the time difference between the vertical earthquake peak and the horizontal earthquake peak was different. $t_{c r}$ was the time of horizontal seismic wave lagging behind vertical seismic wave. Figure 9 (a) shows the longitudinal displacement changed of main girder and bridge pier when $t_{c r}=0.25 \mathrm{~s}$ and $0.5 \mathrm{~s}$, where $t_{c r}$ is the time difference between vertical and horizontal earthquake peak arrival. When $t_{c r}=0.25 \mathrm{~s}$, the maximum longitudinal relative displacement of pier and beam is $55.14 \mathrm{~mm}$. While $t_{c r}=0.5 \mathrm{~s}$, the maximum displacement is $48.11 \mathrm{~mm}$. It can be seen that the different lead time to reach the vertical seismic peak has an effect on the longitudinal displacement of the structure.
In order to further study the influence of different arrival time difference of seismic waves on longitudinal displacement, the interval $t_{c r}=0.05 \sim 0.5 \mathrm{~s}$ was selected for analysis. It can be seen that although different vertical seismic peak duration will affect the maximum longitudinal relative displacement of the girder and pier, the influence is limited. The maximum relative displacement is concentrated in the interval of $3 \sim 5 D_{\max }$, where $D_{\max }$ is the maximum longitudinal relative displacement when separation is ignored.

5.4. Effect of Bearing Stiffness on Longitudinal Displacement. Figure 10 shows the separation times and maximum longitudinal relative displacements of girder and pier at different $V / H$. The structure does not separate at lower $V / H$. The maximum relative longitudinal displacement of piers is at a small value. With the increase of $V / H$, when separation occurs, the deformation at the top of the pier will increase greatly for the high pier bridge. The number of separation times between girder and pier increases 
monotonously. However, the maximum longitudinal displacement fluctuates with the increase of separation times.

\subsection{Effect of Separation Times on Longitudinal Displacement} of Bridge. Through the above calculation, it can be concluded that the structure separation time has strong randomness under different conditions. In order to study the influence of separation times on the longitudinal displacement, a new flowchart is compiled. The specific process is shown in Figure 11. Due to the uncertainty of vertical separation time, the influence of vertical separation time on the longitudinal displacement of the structure is ignored. Each separation time is the worst case of the subsequent displacement response. In order to simplify the calculation model, the following assumptions are made in this section:

(1) Through previous calculations, it can be concluded that the duration of contact and separation was different. Normally, the contact time was longer than the separation time. In the calculation of this study, except for the first contact, the lower limit of the remaining contact time was set to $0.1 \mathrm{~s}$. The upper limit of the separation time was set to $0.1 \mathrm{~s}$.

(2) In each stage of contact and separation, the time point of state change is the moment when the subsequent stage produces the maximum displacement. For example, $t_{1}$ is the time of the first separation, which means that at this point in time, the first separation will produce the largest longitudinal relative displacement.

Figure 12 shows the maximum longitudinal relative displacement of main girder and pier under different separation times at $T=0.25 \mathrm{~s}$. Figures 12 (a) and 12(b) show the maximum possible relative displacements after one and five times of separation, respectively. Black represents contact and red represents separation. When structural separation was ignored, the maximum relative displacement was $22.6 \mathrm{~mm}$. Considering the primary separation of the structure, the maximum relative displacement was $42.6 \mathrm{~mm}$, an increase of $88.5 \%$. When the number of separation times increased to five times, the maximum relative displacement was $101.3 \mathrm{~mm}$, which increased to more than four times of the original. The maximum relative displacement will increase with the increase of the numbers of separation.

Figure 12(c) shows the change of the maximum relative displacement under different separation times, and the former separation times will increase significantly. However, with the increase of separation times, the maximum relative displacement remained stable. The maximum relative displacement was more than four times of that without separation.

For high pier bridges, separation will increase the deformation at the top of the pier, and the maximum possible deformation will enlarge with the increase of the number of separation times, but when the number of separation times exceeds a certain value, the increase of the number of separation times will not significantly affect the deformation at the pier's top.

\section{Conclusions}

This paper uses numerical theoretical simulation to solve the contact and separation of the main girder and the bearing under the action of the strong near-fault vertical earthquake. By using the transient wave characteristic function superposition method and the indirect modal function superposition method, the theoretical solution of the vertical and longitudinal seismic response of the girder and piers under the near-fault seismic excitation was solved. The following concluding remarks could be proposed through numerical simulation:

(1) When $T \approx T_{v}$, vertical seismic excitation can cause bridge separation, but for different heights of piers, the effect of separation on pier deformation was different. For short pier bridge $\left(T \geq T_{s}\right)$, although separation will change the displacement of pier's top, the maximum changed of pier's top has little influence. For high pier bridges $\left(T<T_{s}\right)$, separation can significantly increase the deformation of pier's top. The reason is that the natural frequency of short piers was higher and the displacement caused by the initial velocity at the time of separation is smaller. However, the natural frequency of high piers was lower, so the separation will cause larger subsequent deformation.

(2) Vertical earthquakes may cause a certain number of structural separations and generate collision forces, which are positively correlated with the stiffness of the bearing. In the vertical direction, with the increase of the stiffness, the relative displacement required by the separation of the main girder and pier decreases, which will increase the possibility and numbers of separation. When the main girder and pier contact again, the relative displacement of the main girder and pier in the vertical direction is the compression of the bearing, and the vertical impact force is the product of the deformation of the bearing and the stiffness of the bearing. With the increase of stiffness, the vertical impact force is larger and the duration is shorter.

(3) The stiffness of the support and the time difference of the arrival of vertical horizontal seismic wave will affect the deformation of the bridge pier, which makes the response of the structure after separation have some randomness. When considering the most unfavorable situation, the maximum deformation of the pier top increases with the increase of the number of separations and remains basically unchanged when it exceeds a certain threshold. At the moment, the maximum deformation of the pier top is several times that of ignoring the deformation. The reason is that with the increase of deformation, the subsequent displacement response of the structure separation is gradually affected by the initial position instead of the original velocity, and the damping of the structure also makes the maximum deformation of the pier approach to the critical value and does not increase infinitely. 
From the above conclusions, it can be generally said that the near-fault ground motion may lead to the separation of the bridge. As a result, the deformation of pier's top of high pier bridge was increased and the pier was destroyed. Therefore, for near-fault motions, vertical seismic excitation should be considered in the design of small- and mediumspan bridges.

\section{Data Availability}

The data used to support the findings of this study are available from the corresponding author upon request.

\section{Conflicts of Interest}

The authors declare that they have no conflicts of interest.

\section{References}

[1] H. N. Li, S. Y. Xiao, and L. S. Huo, "Damage investigation and analysis of engineering structures in the Wenchuan earthquake," Jounal of Building Structures, vol. 29, pp. 10-19, 2008.

[2] W. L. Zhuang, Z. Y. Liu, and J. S. Jiang, "Earthquake-induced damage analysis of highway bridges in Wenchuan earthquake and countermeasures," Chinese Journal of Rock Mechanics and Engineering, vol. 28, pp. 1377-1387, 2009.

[3] P. Zhu, M. Abe, and Y. Fujino, "Modelling three-dimensional non-linear seismic performance of elevated bridges with emphasis on pounding of girders," Earthquake Engineering \& Structural Dynamics, vol. 31, no. 11, pp. 1891-1913, 2002.

[4] C. P. Pantelides and X. Ma, "Linear and nonlinear pounding of structural systems," Computers \& Structures, vol. 66, no. 1, pp. 79-92, 1998.

[5] P. K. Malhotra, "Dynamics of seismic pounding at expansion joints of concrete bridges," Journal of Engineering Mechanics, vol. 124, no. 7, pp. 794-802, 1998.

[6] R. Jankowski, K. Wilde, and Y. Fujino, "Pounding of superstructure segments in isolated elevated bridge during earthquakes," Earthquake Engineering \& Structural Dynamics, vol. 27, no. 5, pp. 487-502, 1998.

[7] N. Chouw and H. Hao, "Study of SSI and non-uniform ground motion effect on pounding between bridge girders," Soil Dynamics and Earthquake Engineering, vol. 25, no. 7, pp. 717-728, 2005.

[8] M. A. Saadeghvaziri and A. R. Yazdani-Motlagh, "Seismic behavior and capacity/demand analyses of three multi-span simply supported bridges," Engineering Structures, vol. 30, no. 1, pp. 54-66, 2008.

[9] C.-J. Wang and M.-H. Shih, "Performance study of a bridge involving sliding decks and pounded abutment during a violent earthquake," Engineering Structures, vol. 29, no. 5, pp. 802-812, 2007.

[10] R. DesRoches and S. Muthukumar, "Effect of pounding and restrainers on seismic response of multiple-frame bridges," Journal of Structural Engineering, vol. 128, no. 7, pp. 860-869, 2002.

[11] S. -H. Kim, S. -W. Lee, and H. -S. Mha, "Dynamic behaviors of the bridge considering pounding and friction effects under seismic excitations," Structural Engineering and Mechanics, vol. 10, no. 6, pp. 621-633, 2000.

[12] K. Bi, H. Hao, and N. Chouw, "Influence of ground motion spatial variation, site condition and SSI on the required separation distances of bridge structures to avoid seismic pounding," Earthquake Engineering \& Structural Dynamics, vol. 40, no. 9, pp. 1027-1043, 2011.

[13] S. E. Abdel Raheem, "Pounding mitigation and unseating prevention at expansion joints of isolated multi-span bridges," Engineering Structures, vol. 31, no. 10, pp. 2345-2356, 2009.

[14] J. E. Padgett and R. Desroches, "Three-dimensional nonlinear seismic performance evaluation of retrofit measures for typical steel girder bridges," Engineering Structures, vol. 30, no. 7, pp. 1869-1878, 2008.

[15] A. Ruangrassamee and K. Kawashima, "Control of nonlinear bridge response with pounding effect by variable dampers," Engineering Structures, vol. 25, no. 5, pp. 593-606, 2003.

[16] R. Jankowski, K. Wilde, and Y. Fujino, "Reduction of pounding effects in elevated bridges during earthquakes," Earthquake Engineering \& Structural Dynamics, vol. 29, no. 2, pp. 195-212, 2000.

[17] A. J. Papazoglou and A. S. Elnashai, "Analytical and field evidence of the damaging effect of vertical earthquake ground motion," Earthquake Engineering \& Structural Dynamics, vol. 25, no. 10, pp. 1109-1137, 1996.

[18] J. Yang and C. M. Lee, "Characteristics of vertical and horizontal ground motions recorded during the Niigata-ken Chuetsu, Japan earthquake of 23 October 2004," Engineering Geology, vol. 94, no. 1-2, pp. 50-64, 2007.

[19] M. R. Button, C. J. Cronin, and R. L. Mayes, "Effect of vertical motions on seismic response of highway bridges," Journal of Structural Engineering, vol. 128, no. 12, pp. 1551-1564, 2002.

[20] Y. Bozorgnia and K. W. Campbell, “The vertical-to-horizontal response spectral ratio and tentative procedures for developing simplified $\mathrm{V} / \mathrm{H}$ and vertical design spectra," Journal of Earthquake Engineering, vol. 8, no. 2, pp. 175-207, 2004.

[21] D. Wang and L. Xie, "Attenuation of peak ground accelerations from the great wenchuan earthquake," Earthquake Engineering and Engineering Vibration, vol. 8, no. 2, pp. $179-188,2009$.

[22] Y. Bozorgnia, M. Niazi, and K. W. Campbell, "Characteristics of free-field vertical ground motion during the Northridge earthquake," Earthquake Spectra, vol. 11, no. 4, pp. 515-525, 1995.

[23] Y. Zuo, G. J. Sun, and H. J. Li, “Comparison and research of unseating prevention measures in seismic codes of China and foreign countries," Journal of Disaster Prevention and Mitigation Engineering, vol. 36, pp. 617-623, 2016.

[24] N. Chouw and H. Hao, "Pounding damage to buildings and bridges in the 22 February 2011 Christchurch earthquake," International Journal of Protective Structures, vol. 3, no. 2, pp. 123-139, 2012.

[25] H. B. Yang, X. C. Yin, H. Hao, and K. Bi, "Theoretical investigation of bridge seismic responses with pounding under near-fault vertical ground motions," Advances in Structural Engineering, vol. 18, no. 4, pp. 452-468, 2015.

[26] Y. F. Xing and L. J. Wang, "Analysis of wave propagation in the built-up structures of rod-beam and beam-beam," Journal of Beijing University of Aeronautics and Astronautics, vol. 30, no. 6, pp. 520-523, 2013.

[27] CJJ 166-2011, Code for Seismic Design of Urban Bridges, Ministry of Housing and Urban-Rural Development of the People's Republic of China, Beijing, China, 2011. 